\title{
Analysis of the concept of powerlessness in individuals with stroke
}

\author{
Renan Alves Silva' \\ Álissan Karine Lima Martins ${ }^{2}$ \\ Natália Barreto de Castro ${ }^{3}$ \\ Anna Virgínia Viana ${ }^{4}$ \\ Howard Karl Butcher ${ }^{5}$ \\ Viviane Martins da Silva ${ }^{6}$
}

\section{Analysis of the concept of powerlessness in individuals with stroke}

Objective: To identify and analyze the concept of the powerlessness in individuals with stroke, according to the NANDA-I Taxonomy. Methods. Concept analysis from online access of four databases using the descriptors: impotence; helplessness, learned; Stroke, depression in languages: Portuguese, English and Spanish. Results. The critical attributes of the feeling of powerlessness are: fragility, helplessness, lack of control, and power to achieve the proposed results for recovery and adaptation. Eleven new antecedents were found. It is recommended to reformulate three antecedents present in the taxonomy. Fourteen consequent were found. It is suggested to amend three consequential from the review. Conclusion. With the analysis, a more complete concept of the powerlessness was elaborated allowing clarifying the critical attributes that, in turn, will help the rehabilitating nurse to recognize the signs and symptoms and to strengthen mechanisms of tolerance and resistance to stress.

Descriptors: helplessness, learned; stroke; standardized nursing terminology; concept formation; nursing diagnosis.

\section{Análisis del concepto de Sentimiento de impotencia en individuos con accidente cerebrovascular}

Objetivo. Analizar el concepto de sentimiento de impotencia en individuos con accidente cerebrovascular, según la Taxonomía de NANDA-I. Métodos. Análisis de concepto a partir del acceso on-line a cuatro bases de datos utilizando los descriptores: impotencia; desamparo aprendido; accidente vascular cerebral, depresión en los idiomas portugués, inglés y español. Resultados. Los atributos críticos del sentimiento de impotencia son: fragilidad, desamparo, falta de control y el no poder

\footnotetext{
1 Nurse, Master. Federal University of Ceará, Brazil. email: renan.dehon@gmail.com

2 Nurse, Ph.D. Professor, Regional University of Cariri, Brazil. email: alissan.martins@urca.br

3 Nurse, Master. Federal University of Ceará, Brazil. email: nataliabarretodecastro@hotmail.com

4 Nurse, Master. Federal University of Ceará, Brazil. email: annavirginiaviana@gmail.com

5 Nurse, Ph.D. Center for Nursing Classification and Clinical Effectiveness. College of Nursing. University of Iowa, USA. email: howard-butcher@uiowa.edu

6 Nurse, Ph.D. Professor, Federal University of Ceará, Brazil. email: viviane.silva@outlook.com
}

Conflicts of interest: none.

Received: June 8th 2017.

Accepted: August 23rd 2017.

How to cite this article: Silva RA, Martins AKL, Castro NB, Viana AV, Butcher HK, Silva VM. Analysis of the concept of powerlessness in individuals with stroke. Invest. Educ. Enferm. 2017; 35(3):306-319

DOI: 10.17533/udea.iee.v35n3a07 
alcanzar los resultados propuestos para la recuperación y adaptación. Se encontraron once nuevos antecedentes. Se recomienda reformular tres antecedentes presentes en la taxonomía. Se evidenciaron 14 consecuencias y se sugiere alterar tres a partir de la revisión. Conclusión. Con este análisis se elaboró un concepto más completo del sentimento de impotencia, permitiendo clarificar los atributos críticos que, a su vez, ayudará al enfermero rehabilitador a reconocer las señales y síntomas, como también a fortalecer los mecanismos de tolerancia y enfrentamiento al estrés.

Descriptores: desamparo adquirido; accidente cerebrovascular; terminología normalizada de enfermería; formación de concepto; diagnóstico de enfermería

\section{Análise do conceito de Sentimento de impotência em indivíduos com acidente vascular encefálico}

Objetivo. Identificar e analisar o conceito do sentimento de impotência em indivíduos com acidente vascular

\section{Introduction}

In this study, the objective was to analyze the concept, defining characteristics, related factors of the powerlessness (Nursing Diagnosis 00125) in individuals who survived to stroke. A delimitation of the study in this population is supported, since is a serious health problem around the world, with high rates of mortality, morbidity and acquired incapacity. ${ }^{(1)}$ This fact becomes worrying for nursing care, because, this neurological disorder has a negative impact in the way of life; making the patient dependent on caregivers, constantly. The referred diagnosis is established according to NANDA International, Inc. Nursing diagnostic improvement is important for clinical practice because the nurse uses the nursing process while caring for a patient; take data by means of techniques, materials and instruments identify the main affected human responses in which they are to be solved, plans what results need to be achieved and maximized to trace effective, adequate and timely interventions in the process of neurological rehabilitation and evaluation if interventions were satisfaction in the resolution of the previous trial. ${ }^{(2)}$ encefálico, segundo a Taxonomia da NANDA-I. Métodos. Análise de conceito a partir de acesso online a quatro bases de dados utilizando os descritores: impotência; desamparo aprendido; acidente vascular cerebral, depressão nas línguas português, inglês e espanhol. Resultados. Os atributos críticos do sentimento de impotência são: fragilidade, desamparo, falta de controle e poder para alcançar os resultados propostos para recuperação e adaptação. Encontrouse onze novos antecedentes. Recomenda-se reformular três antecedentes presentes na taxonomia. Evidenciouse quatorze consequentes; sugere-se alterar três consequentes a partir da revisão. Conclusão. Com a análise elaborou-se um conceito mais completo do sentimento de impotência permitindo clarificar os atributos críticos que, por sua vez, auxiliará ao enfermeiro reabilitador reconhecer os sinais e sintomas e fortalecer mecanismos de tolerância e enfrentamento ao estresse.

Descritores: desamparo aprendido; acidente vascular cerebral; terminologia padronizada em enfermagem; formação de conceito; diagnóstico de enfermagem.

For the accomplishment of this study, a concept analysis was performed. This method must be performed to identify particular and characteristic attributes. In Nursing, a range of models of concept analysis stand out, highlighting that described by Walker and Avant. ${ }^{(3)}$ These authors propose a modified and simplified analysis based on previously constructed models. Furthermore, this model has direct reference to nursing and language classification systems.

Among the nursing diagnoses experienced by patients after stroke, there is the powerlessness, in which NANDA-I defines as the "lived experience of lack of control over a situation, including a perception that the actions themselves do not affect, in a significant way, a result". (2) This study started from the premise that the conceptual definition does not present precise and clear attributes for the rehabilitating nurse to infer this diagnosis in the referred study population. Thus, it is essential to identify possible adaptations or changes in the definition of nursing diagnosis, defining characteristics and related factors, since, 
is observed, in recent years, considerable attention to the development of systematized nursing knowledge as a science, discipline and profession. This nursing diagnosis interferes negatively in nursing care planning due to functional deficiencies; repercussions on low levels of rehabilitation and quality of life. It presents a high incidence rate, recurrence and mutilation ranging from $20 \%$ to $50 \%$, persisting from three to six months in the chronicity period. ${ }^{(4)}$

The relevance of this study is based on the scarcity of studies of concept analysis and in the understanding of the need for diagnostic refinement studies in specific populations, such as those individuals who survived after a stroke. Also, studies that evaluate the defining characteristics and related factors contained in the NANDA International taxonomy are insufficient to infer this nursing diagnosis. Thus, the validation of nursing diagnoses already accepted is fundamental for the growth of nursing as a care science and also to provide greater social visibility to the professional practice of nurses. To develop the stages of concept analysis proposed by Walker and Avant, it is indispensable to broaden the search in the literature by means of a solid, specific revision with the aim of identifying relations or theoretical components that underlie the construct and base the formulation of each item of the tool in construction. ${ }^{(3)}$ In this study, it was decided to guide the steps proposed by Whittemore and Knafl(5) for the literature review. This method synthesizes results from relevant and globally recognized research facilitating the incorporation of evidence for the nursing diagnosis, which is, speeding up the transfer of new knowledge to practice.

In this sense, the clear and precise definition of concepts solves possible problems of understanding between professionals of the nursing team and in relation to other professions. Moreover, the emphasis on concept analysis plays a relevant role in the development and application of knowledge in practice. The clarification of concepts promotes the organization of the experience, facilitating communication between individuals. So, when the definition or attributes of a concept are unclear, its ability to assist in tasks is impaired. For this reason it is necessary the interest of nurses to develop the theme, so that the desired degree of clarity of the concepts of interest can be clarified to the maximum. ${ }^{(6)}$

Diagnostic accuracy based on related factors and defining characteristics that represent the concept is a key part of designing a care plan that describes the patient's health needs. Therefore, concept analysis constitutes the initial stage of validation studies of nursing diagnoses for providing a broader understanding of the topic of interest.

\section{Methods}

An integrative literature review was carried out with the purpose of synthesizing the essential scientific findings to the evolution of nursing science. ${ }^{(5)}$ Since this study is about presenting the knowledge produced about the powerlessness establishing causality and prognosis, was used a PICO strategy, which represents an acronym for Patients, Intervention, Comparison and Outcomes: P- Patients who survived stroke; I- nursing diagnosis powerlessness; $\mathrm{C}$ - nursing diagnosis powerlessness; and $\mathrm{O}$ - antecedents and consequents. In this sense, it was formulated as a guiding question: What is the definition, antecedents and consequent of the diagnosis of nursing feeling of impotence in individuals with stroke?

For the bibliographic selection, the following databases were used: Latin American and Caribbean Health Science Literature (Lilacs), National Library of Medicine National Institutes of Health (Pubmed) and Cumulative Index to Nursing and Allied Health Literature (Cinahl). The controlled descriptors used to survey the studies were: Impotence OR Learning Disability OR Depression AND Stroke, in Portuguese, English and Spanish. It is noteworthy that the key words learned helplessness and depression were inserted, due to the main consequence related to the diagnosis being studied, being identified in most articles referenced by NANDA-I, Inc.

The following inclusion criteria were established: complete articles available electronically; Studies published after 2005, year in which the concept 
was modified by the Diagnostic Development Committee (DDC) of NANDA-I in the city of Chicago, United States of America, until the last full year of 2015; research with individuals over 18 years of age. The characteristics adopted as criteria for eligibility were: answer the guiding questions, be written in Portuguese, English or Spanish. As criteria for exclusion: studies in editorial formats, letters to the editor, book chapters, guidelines, reviews and secondary studies. The selection of the articles was carried out between July and September 2016. The evaluation of the studies was performed by means of the classification of evidence forces. ${ }^{(8)}$ In this stage, the information extracted from the studies was identified and documented in a concise manner, which possibilities explore identification data of the study, methodological characteristics, results obtained and conclusions. This step was performed after the selection of the primary studies. After the characterization of the selected articles, were proceeded with the steps proposed by the concept analysis model to answer the guiding questions of this study during the months of October and November of 2016.

The search was performed with the crossing of the selected descriptors, initially 3007 references were found in PUBMED, 138 in LILACS and 1005 in CINAHL. After reading the articles and applying the inclusion criteria, 35 studies grounded the analysis of the Concept powerlessness in individuals with stroke, being 23 of Pubmed / Medline and 12 of CINAHL.

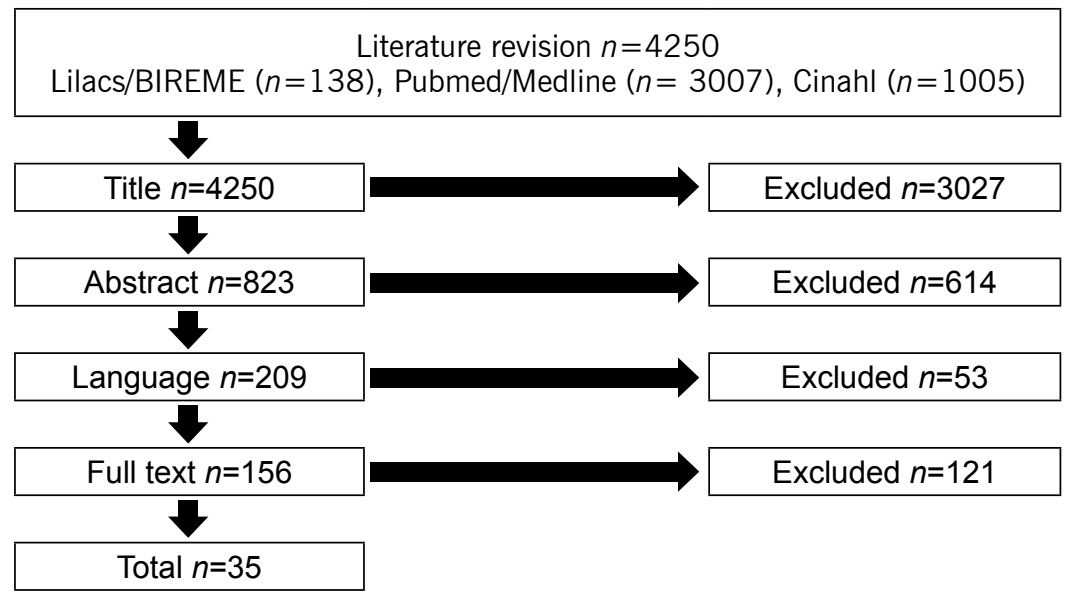

Figure 1. Flowchart of included studies.

The nursing diagnosis review was developed based on the concept analysis, which is the first step in the validation of the process and corresponds to the theoretical structure, in which it is sought to build knowledge about the phenomenon from the establishment of critical attributes, antecedents and consequents of the concept that wants to study. To assist the execution of the analysis of concepts were used the model proposed by Walker and Avant. (3) This model clarifies the knowledge about the concept, distinguishes the true defining characteristics and identifies the attributes considered irrelevant. It is composed of eight stages that interact with one 
another: concept selection; determination of the objectives of the analysis; identification of possible uses of the concept; determination of critical or essential attributes; construction of a model case; identification of additional cases: borderline, related, contrary, fabricated and illegitimate; antecedent and consequent identification; ${ }^{(3)}$ with this, every nursing diagnosis is a concept that needs to be elaborated by systematic means, since it allows to know its structure and use in the different practices and disciplines. ${ }^{(3)}$

In this study the first seven stages of the conceptual analysis model were performed. Next, were established relations between the antecedents found in the literature with the related factors contained in the Taxonomy of NANDA International; as well as consequent and defining characteristics of the diagnosis presented in tables.

\section{Results}

Most of the articles were developed in North America (31.4\%) and Asia (31.4\%), and were produced by doctors (51.4\%) and nurses (20\%). The United States of America had the highest percentage of production (28.6\%, $n=10$ ). From 2008, 32 studies (91.3\%) were published. Regarding the subjects' age range, the majority of studies involved the elderly (62.9\%), followed by older adults. Among the research scenarios were: hospital $(45.8 \%)$, followed by the rehabilitation unit (34.3\%). Most were cohort and case-control studies, well delineated (62.9\%). The strength of evidence of most of the articles analyzed was distributed in levels III and IV, emphasizing that there was scientific evidence considered strong; since no systematic review or meta-analyzes were analyzed, due to the criteria defined from PICOT. Following the steps proposed by the concept analysis, were proceeded with the identification of possible uses of the concept and the best scientific evidence about the powerlessness in individuals with cerebrovascular events due to clinical morbidity. In continuity, were followed the other steps of the Walker and Avant model. (3)

\section{Identification of possible uses of the concept}

It was evidenced in the 35 analyzed studies that the concept of powerlessness is a response to the process of recovery and/or adaptation to stressful or traumatic events. This concept is used by health professionals, especially medicine, nursing and psychology; since this response is dysfunctional affective, behavioral or emotional.

\section{Critical or essential attributes of the concept of "powerlessness"}

Among the 35 publications analyzed, $65.7 \%$ ( $n=23$ ) defined the concept of powerlessness; evidenced by the clinical observation of this phenomenon or the use of instruments or scales to track depressive events, suicidal tendencies, life purpose and self-esteem. The critical attributes of the diagnosis under study are: fragility, helplessness, lack of control and power to achieve proposed results in the process of recovery and/or adaptation.

\section{Construction of a model case}

C.A.V.M, 60 years old, male, married, excouncilor, accompanied by the Family Health Strategy to perform daily self-care activities in relation to skin, bladder catheterization and nasal oxygen administration. Client enrolled in the Home Care Program with hemorrhagic stroke, with lower and upper limb impairment, as well as visual and auditory acuity, in addition to the areas of Wernicke and Broca. He performs intensive physical and motor rehabilitation activities five times a week with the physiotherapist. During the home nursing consultation, when an instrument of evaluation of the degree of incapacity was applied, it was observed a total dependence on the basic and instrumental activities of daily living, with constant reporting of frustration and the expression of dissatisfaction with life. As a result of stroke, he presents hemiplegia, hemiparesis, homonymous hemianopsia, ataxia, dysarthria, hypotonia, postural imbalance; making difficult to exercise the social function assigned 
before the neurological episode, demonstrating resentful, angry, feeling guilty and sad. The wife claims change in partner behavior, reporting two suicide attempts in the past month. The patient presents suicidal ideation and feeling of less value constantly. When questioned about the purpose of life, there was frustration about the value given to it. Facing the process of home care is very common the presence of children, neighbors, friends encouraging cooperation before the interventions carried out by the multiprofessional team of the reference service of the municipality, faced himself with this situation is ashamed. The eldest son helps in the execution of self-care activities by encouraging him to brush his teeth as he pleases; when challenged to perform this care, the son reports that he is aggressive. C.A.V.M. cannot achieve the minimum expected results nor monitor progress in the care process.

\section{Construction of an otherwise}

M.N.L.V., 58, female, teacher, divorced, accompanied by the Family Health Strategy to monitor blood pressure and glycemic levels, activities to encourage daily self-care, medication administration, special care for continuous thrombolytic therapy and control of weight. Client enrolled in the Home Care Program for patients with ischemic stroke, with involvement of the lower and upper limbs. The team carries out a weekly home visit in order to identify and control adherence to the pharmacological and nonpharmacological therapeutic regimen. M.N.L.V is in the sixth month of post-acute rehabilitation. During the home nursing consultation, a disability assessment instrument was applied, and functional independence was observed in basic, instrumental and advanced activities of daily living. The patient is motivated to return to her professional activities as soon as possible. She is willing, enthusiastic to participate in activities related to the control of the therapeutic regimen, describes actions to reduce risk factors, expresses desire to control and prevent the onset of neurological sequela, accepts her own decisions about her state of health, follows a careful and healthy diet, practice light to moderate physical exercise as established by the doctor of the service. In relation to the purpose of life, perceives satisfaction as to the value given to her. Throughout home visits is very common, the presence of children, neighbors, friends encouraging cooperation and participation in the interventions made by both the nursing and the multiprofessional team of the referral service of the municipality, shows joy and receptive to all that the visit.

In this case, it is explicit that M.N.L.V does not present the nursing diagnosis powerlessness. In this way, are perceived critical attributes contrary to fragility (exercises that gradually restore mobility and body balance, functional independence in the accomplishment of basic, instrumental and advanced activities of daily life, being willing to participate in the care); to helplessness (Satisfaction with life) and lack of power and control (enthusiastic to participate in activities related to the control of the therapeutic regime, expressed desire to control and prevent the onset of neurological and cognitive sequela, making decisions appropriate to her state of health ).

\section{Identification of antecedents and consequents}

In the current NANDA-I taxonomy, the nursing diagnosis under study is composed of three related factors and eight defining characteristics. With this study, it is recommended to modify the factor related health care environment to offer unsatisfactory care; as well as the dismemberment of unsatisfactory interpersonal interaction in two antecedents: lack of social support, lack of social participation. Regarding the disease-related regimen in three antecedents: low self-esteem, lack of motivation and lack of interest. Also, were suggested the inclusion of the new antecedents: type of injury, severity of the injury, unpredictable course, location of the lesion and limitation of body mobility.

Regarding the defining characteristics the inclusion of three consequent is indicated: fatigue, cognitive impairment existing in time or progressive, time of physical and motor rehabilitation. Were suggested disaggregating the frustration report about the inability to perform previous activities 
in three, namely: basic activities of daily living, instrumental activities of daily life and advanced daily life; as well as the dismemberment of lack of control in suicide attempts and life purpose. Also, it is indicated that the change in the defining characteristic does not participate in care by level of participation in rehabilitation.

It is observed that the antecedents most cited in the literature (type of injury, severity of the injury, unpredictable course and lack of social support) (Table 1), as well as the consequent ones (difficulties to express thoughts verbally and decide on their state of health, existing cognitive impairment in time or progression, level of participation in rehabilitation and time of physical and motor rehabilitation) (Table 2), do not make up the NANDA-I, Inc. indicators. In addition, two defining characteristics (level of rehabilitation participation and Suicide attempts) were evidenced in the literature with nomenclatures different from those in NANDA-I.

Table 1. Related factors and antecedent found in the analysis of the studies

\begin{tabular}{ll}
\hline \multicolumn{1}{c}{ Related factors of NANDA-I } & \multicolumn{1}{c}{ Antecedents - concept analysis } \\
There are no correspondents & Type of injury $(n=9)$ \\
There are no correspondents & Severity of injury $(n=6)$ \\
There are no correspondents & Unpredictable course $(n=6)$ \\
There are no correspondents & Location of the lesion $(n=5)$ \\
There are no correspondents & Limitation of body mobility $(n=5)$ \\
Unsatisfactory interpersonal interaction & Lack of social support $(n=6)$ \\
Unsatisfactory interpersonal interaction & Lack of social participation $(n=3)$ \\
Health care environment & Unsatisfactory care offers $(n=4)$ \\
Regime related to the disease & Low self-esteem $(n=3)$ \\
Regime related to the disease & Lack of motivation $(n=3)$ \\
Regime related to the disease & Lack of interest $(n=1)$ \\
\hline
\end{tabular}

Table 2. Definitive and consequents characteristics found in the analysis of the studies

\section{Defining characteristics NANDA-I}

Dependence on others

Depression due to physical deterioration

Report of doubt about function performance

There are no correspondents

There are no correspondents

There are no correspondents

There are no correspondents

There are no correspondents

There are no correspondents

Non-participation in care

\section{Consequences - concept analysis}

Dependence on others $(n=6)$

Depression due to physical deterioration $(n=7)$

Report of doubt about function performance $(n=5)$

Report of frustration about the inability to perform the basic activities of daily living $(n=3)$

Report of frustration about the inability to perform the instrumental activities of daily living $(n=3)$

Report of frustration about the inability to perform the advanced activities of daily living $(n=1)$

Fatigue $(n=3)$

Existing or progressive cognitive impairment $(n=7)$

Physical and motor rehabilitation time $(n=4)$

Level of participation in rehabilitation $(n=5)$ 
Table 2. Definitive and consequents characteristics found in the analysis of the studies. (Cont.)

\begin{tabular}{ll}
\hline There are no correspondents & $\begin{array}{l}\text { Difficulty to express their thoughts verbally and to decide on their state } \\
\text { of health }(n=8)\end{array}$ \\
Report of lack of control & Suicidal attempts $(n=1)$ \\
There are no correspondents & Purpose of life $(n=1)$ \\
Report of shame & Shame $(n=1)$ \\
Report of alienation & There are no correspondents \\
\hline
\end{tabular}

Based on the appreciation of the definitions of powerlessness and the critical attributes essential to this concept evidenced in the literature is constituted from the model cases and contraries presented a unique definition, objective and clear that contemplates the results of this conceptual analysis: Perceived emotional response faced with the process of coping with the disease or physical disability, presenting fragility, helplessness and lack of control and power to achieve the proposed results during functional recovery and/or adaptation.

\section{Discussion}

In recent years there has been an exponential increase in the production of nursing knowledge through the analysis of concepts, validation studies and diagnostic differentiation. Most of the selected studies have been published in countries in North America and Asia. Regarding the year of publication, almost all the articles are from the 2000s, with a growing increase after 2008. It is noted that one of the decisive factors for the production of knowledge was the consolidation of postgraduate programs worldwide. ${ }^{(7)}$

The production of knowledge, on the studied concept, involved different areas of health (medicine, nursing, psychology, physiotherapy and physical education). In some articles these were from several areas of health. Identifying this human response is essential for all the professions involved in rehabilitation, no restricting to just one profession. ${ }^{(8)}$ Similarities were found in these areas in the use of the concept from the analysis of the components, because it was identified conceptual elements of the theory of learned helplessness postulated by Seligman. ${ }^{(9)}$ It is envisaged that conceptual definition of diagnosis contained in NANDA-I Taxonomy uses elements of this theory.

Hence, the partnership between nurses and other health professionals is indispensable, as this performs their work as a team, and the exchange of experience strengthens the clinical practice and the look on the patient's situations. In this context, stroke patients with powerlessness may benefit if there is a multidisciplinary team capable of strengthening the mechanisms of coping and tolerance to stress.

In Nursing, it is observed that the NANDA-I diagnostic classification system is one of the most well-known, widely and used worldwide, since it contributes to the standardization of nurses' language, with the purpose of assisting in clinical judgment and enhancing development of nursing as science, discipline and profession. (10) It is also seen that in this taxonomic classification system all diagnostic categories are derived from concepts and present theoretical models or formulations ${ }^{(11)}$ to give meaning to the observations of physiological, psychic, social, religious and spiritual phenomena, going through continuous analyzes according to studies found in the literature. ${ }^{(12-19)}$

As already mentioned, the conceptual definition of powerlessness (00125) standardized by NANDA-I is "lived experience of lack of control over a situation, including a perception that one's actions do not significantly affect a result."(2). In previous studies whose objective was to highlight the concept of impotence, the authors did not indicate changes in the definition of the studied 
concept, reinforcing most of its elements as defined by NANDA-I. They emphasized that this response is the absence of power, capacity, authority to act, influence own life, and control events. (20-26) However, should be considered that this human response is due to chronic health conditions and congenital or acquired physical disability.

The present study identified elements of the concept already existing in previous studies presented to DDC of NANDA-I (5), as well as new elements that make up the concept of powerlessness. Among the findings of the literature ${ }^{(20-26)}$ and those of the present study, were verified differences in relation to the attributes of the concept and temporal characteristics pointed out (antecedent, consequent), as well as differences in the relation of ideas regarding the concept of impotence.

It should be noted that the concept defined in this study is evolutionary, since it considers the defining characteristics "Dependence of others" and "Depression by physical deterioration", "Report of doubt about role performance", "Difficulty to express verbally thoughts and decide on their specific health", specific to infer this diagnosis. It should be noted that these indicators were not considered critical in the diagnostic definition presented by NANDA-I. ${ }^{(2)}$

Twenty three definitions of powerlessness were identified. It is observed that this nursing diagnosis presents a broad concept with many critical attributes: fragility, helplessness, lack of power and control, which cannot always be measured. It should be noted that the contributions of this study to the improvement of the nursing diagnosis of interest is the inclusion of two new attributes: fragility and helplessness. These findings are in line with a study developed in Brazil that constructed an instrument to measure feelings of impotence, classified in three dimensions: inability to perform behaviors, loss of control in relation to decision making and interpretation of events, and emotional response to control of situations. ${ }^{(27)}$

According to some authors, the powerlessness is the common state experienced in the process of illness, resulting from the burden caused by the change in the social and family role, having an impact on the effective performance of rehabilitation and functional dependence. (28) It can be conceptualized as emotional response due to functional and cognitive deficiency, with reports of weakness, lack of physical vigor to perform daily activities, inhibition of impulsive behavior to participate in the rehabilitation process. $^{(29)}$ It is stated that it is the low ability to develop basic activities of daily living, reduction in social participation, showing unwillingness to participate in planned activities, poor recovery, and reduced rehabilitation, and a lack of interest in returning to work. ${ }^{\left({ }^{30}\right)}$ In this way, getting sick is a global process involving physiological and emotional responses. These findings go against the results that power and control are determined by physical vigor, psychological resilience, social support, positive self-concept, energy, knowledge, discernment, motivation, and belief system.

Fragility becomes an essential attribute to infer the powerlessness among individuals affected by stroke. It can be measured by observing unintentional weight loss, greater than $4.5 \mathrm{~kg}$ or greater than $5 \%$ of body weight in the last year; self-reported fatigue; decreased palmar grip strength, measured with dynamometer and adjusted for sex and body mass index; low level of physical activity, measured by weekly energy expenditure in kcal (based on self-report of activities and physical exercises performed) and adjusted by gender; decrease in gait activity in seconds: distance of $4.5 \mathrm{~m}$ adjusted for sex and height. ${ }^{(31)}$

The attribute "helplessness" is verified by verbal reporting. It presents as indicators common feelings of depressive mood: marked and unhappy discouragement throughout the day; pessimism about the future; constant reports that his life is synonymous of failure; cry and think people do not like him anymore; thinks things can not improve; it is perceived as a hindrance in the lives of others; dissatisfied and bored with everything; feels guilty, disappointed with himself. ${ }^{(32,33)}$

With regard to the attributes "lack of power and control" already contained in the current taxonomy 
are indivisible. They affect the ability to make decisions regarding their state of health. They are antonyms to the word power, which means to have the faculty, to have possibility, to deliberate. ${ }^{(21)}$ In this way, power is the actual or potential ability or capacity to achieve goals through interpersonal processes. Previous studies on power evidence that it is the person's ability to influence what happens to them. Power can be structured into five categories: explorer, manipulator, competitor, nutritious and integrative. They interact with one another by giving and caring for oneself, directing others toward self-care and always giving the last word in decisions about self-care. ${ }^{(22)}$ In the individual who survived stroke, functional, cognitive, affective and behavioral impairments, sometimes limits or impedes role performance.

It is verified that the causal factors can be categorized in: related to clinical condition, social bond, quality of care and emotional. In this sense, the type, severity, course and location of the lesion are decisive factors for the increase of hospitalization period, mortality rate in the first years, changes in mood control, physical immobility, expressive or receptive aphasia, facial paresis, hospital readmissions, and fatigue. Limitation in mobility triggers repeated episodes of melancholia. (30) It affects both body members with perceptible regions with spasticity and contractures making it difficult to reach and manage objects that causes an inoperable sense of less value. ${ }^{(34)}$

The lack of social support and social participation are predictive factors for worse functional outcomes in the domains of cognition, mood and affectivity. ${ }^{(11,28,30,32,34-39)}$ With this, family and community reintegration favors the process of linking and communicating, returning to work and participating in community recreational activities. (37) The categorization of "quality of care" presented an antecedent: offering unsatisfactory care. This factor has repercussions on the confidence and contentment of the patients favoring adherence to the therapeutic regimen. This opinion is essential from the initial phase of treatment. ${ }^{(39-41)}$

It was decided to restructure the disease-related regimen factor in low self-esteem, lack of motivation and interest. These determinants have repercussions on functional recovery influencing the adaptation of the problem and the functional results on the motor and cognitive domains. ${ }^{(29,35-}$ 36,42-44) Feelings of loss of confidence in oneself and physical control, threatening the self, starting to interfere with performance, social self-esteem and appearance are experienced because of low selfesteem. ${ }^{(35,45,46)}$ Low self-esteem has repercussions on dependence, depersonalization, functional difficulty and lack of control(32). The studies indicate that the occurrence of aphasia impairs verbal communication $^{(35)}$; low visual acuity, decreased cognitive function, and unilateral neglect directly affect moods by being angry, frustrated, sad, and apprehensive. ${ }^{(36)}$ Another relevant fact is that lack of motivation is due to the low purpose of life. After illness, patients are considered obstacles to family and society. Factors such as lack of momentum or persistence are triggers for low life expectancy. $(29,42,44)$ Lack of interest is a decisive element in the participation of rehabilitation, leading to an increase in the time needed for recovery; besides causing stress overload in the caregiver. ${ }^{(42)}$

As a result of the powerlessness, functional dependence has been found to cause innumerable damages, including: frequent hospitalizations, ${ }^{(41)}$ prolonged recovery, increased mortality, ${ }^{(47)}$ and impairment of functional outcomes. ${ }^{(48)}$ This indicator is related to the: advanced age, medical comorbidities, stroke severity, decreased cognition, ${ }^{(14)}$ and the presence of aphasia. ${ }^{21)}$ Doubt regarding role performance is marked by negative attitudes and beliefs that compromise motivation and participation .

The frustration of the inability to perform basic, instrumental and advanced activities of daily living are signs of a feeling of worthlessness. ${ }^{(30,46,48)}$ It was decided to categorize the previous activities, since, the studies show the functional independence in these three levels. The report of fatigue is constant in the patients, showing themselves tired, unable to maintain habitual routines, necessitating a period of rest between one activity and another. ${ }^{(35)}$ Another consequence of highlighting is cognitive impairment. It is the result of the effects of 
cerebrovascular lesions that affect the domains of executive language, spatial and visual perception, learning and memory. ${ }^{(37,38,43)}$

Studies point out that individuals with stroke are able to participate actively in an intense rehabilitation regimen of at least three hours a day, achieving better functional results over a short period of time. ${ }^{(49)}$ Despite the implementation of intensive programs, many continue to experience post-discharge deficiency, presenting common feelings such as inferiority and fragility. The evidence suggests that rehabilitation during hospitalization improves short-term survival and functional capacity. However, long-term benefits are not perceived. Thus, it is urged that rehabilitative practices should not be discontinued at discharge before the completion of three months ${ }^{(50)}$, and especially in the six weeks after the cerebrovascular event. ${ }^{(34)}$ When the patient requires more than six months bigger are the rates of depression up to the third year associated with severe disability status. ${ }^{(46)}$

The level of participation in rehabilitation worsens functional outcomes increasing the chance of developing depressive episodes. ${ }^{(50)}$ This indicator is one of the ways to identify learning from activities performed, as well as progress in rehabilitation and overall functional prognosis. (29) It is noted that the consequent "Difficulty to express your thoughts verbally and to decide on their state of health" is related to lesion in the left hemisphere, triggering language disorders; being less cheerful and confident in following the prescribed therapeutic regimen. ${ }^{(36)}$ Furthermore, concomitant aphasia is linked to a sense of worthlessness and less value. ${ }^{(33)}$

Studies indicate suicide attempts as a consequence of this nursing diagnosis under study. It has high rates in the first six months post-event, with a mean suicide rate of 83 for every 10,000 affected patients. ${ }^{(51)}$ Undeniably, life purpose is an extremely important component in this diagnosis because it is demarcated by attitudes related to existentialism; to the senses that the individual gives his life, through the selection of value and objective. Still as the most stable and far-reaching goal resulting from the experience of seeking personal satisfaction always directed towards an end opposite to existential frustration. ${ }^{(44)}$ Studies point out that lack of enthusiasm, excitement in living; absence of clear life goals; have no meaning for life and no novelty each day. Then become constant the desire to die, do not work after retirement activities and start do wait death passively. ${ }^{(52)}$

Shame is a psychological condition of negative control from ideas and emotional and psychological states that alter behavior. It is induced by knowledge or awareness of dishonor, disgrace, or condemnation. ${ }^{(45)}$ It can manifest itself slightly or severely, affecting well-being and results against health control; in particular, in the performance (physical self-competence) of basic activities, in social self-esteem (family and community activities) and in the appearance of self-esteem (body image and attractiveness by other people). ${ }^{(45)}$

After the end of the conceptual analysis of the nursing diagnosis powerlessness, it was submitted to the taxonomy of NANDA I for its appreciation and possible changes in the present diagnosis, as well as in the diagnosis of risk of feeling impotent. In view of the identification and analysis of the concept, it was verified as limitation of the present research, the large number of foreign publications evidenced in the integrative review, justified by the frequent involvement of the cerebrovascular accident in many countries, besides Brazil. It is observed that this profile of publications may have influenced the conclusion and limit the generalization of the data to the Brazilian population, thus, it is recommended to carry out new research in other databases.

Conclusion. This study is considered a pioneer in researching the concept of powerlessness experienced by individuals with stroke, since it presented the objective of identifying and analyzing the concept, related factors and defining characteristics of Impotence Feeling. In view of the results, it is pointed out as a limitation the need to follow the consequent steps to the diagnostic validation, among them the content by 
specialists and the clinical validation in individuals with stroke who perform rehabilitation in the postacute and chronic phase of the disease, in order to determine the predictive defining characteristics for diagnostic inference.

This study allowed the recognition of the best scientific evidence to be confirmed before the recognition and inference of this essential nursing diagnosis for the practice of clinical care in people with stroke.

Also, it is verified that the studied diagnosis is a phenomenon of nursing practice in rehabilitation, needing to recognize early signs and symptoms; as well as to establish and strengthen mechanisms of adaptation to the chronic condition. In this sense, it is observed that from this study the nursing diagnosis is more robust, passing from criterion 2.1 (accepted for publication and inclusion in the NANDA-I taxonomy) in the last version 20152017 to 3.1 (applied clinically through synthesis of literature to specific population) in the years to come. It should be emphasized that this study still allowed establishing causal relationships between the antecedents, consequent and the nursing diagnosis of interest.

With the analysis, a more complete and broad concept of the powerlessness was elaborated allowing to clarify the critical attributes that, in turn, will help the rehabilitating nurse to recognize the signs and symptoms and to strengthen mechanisms of tolerance and resistance to stress.

\section{References}

1. Lima ACMACC, Silva AL, Guerra DR, Barbosa IV, Bezerra KC, Oria MOB. Nursing diagnoses in patients with cerebral vascular accident: an integrative review. Rev. Bras. Enferm. 2016; 69(4):738-45

2. Herdman TH, Kamitsuru S. (Ed.). NANDA International nursing diagnosis: Definitions \& classification, 2015-2017. Oxford: Wiley-Blackwell; 2015.
3. Walker LO, Avant KC. Concept development. In: Walker LO, Avant KC. Strategies for theory construction in nursing. 5rd ed. Norwalk: Appleton \& Lange; 2011:109-121.

4. Zhang WN, Pan YH, Wang XY, Zhao Y. A prospective study of the incidence and correlated factors of post-stroke depression in china. PLoS One. 2013; 8(11):78-81

5. Whittemore $R$, Knafl $K$. The integrative review: updated methodology. J. Adv. Nurs. 2005; 52(5):546-53.

6. Fontenele FC, Pagliuca LMF, Cardoso MVLML. Skin care of the newborn: concept analysis. Esc. Anna Nery. 2012; 16(3):480-5.

7. Erdmann AL, Peiter CC, Lanzoni GMM. Brazilian research groups in nursing: comparison of 2006 and 2016 profiles. Rev. Gaúcha Enferm. 2017; 38(2):e69051.

8. Morais EAS, Rojas SSO, Veiga VC. Health indicators in the care for neurocritical patients. Rev. Rene. 2014; 15(2):189-95 .

9. Seligman MEP, Peterson C, Maier SF. Learned helplessness: a theory for the age of personal control. New York: Oxford University Press; 1975.

10. Carvalho EC, Cruz DALM, Herdman TH. Contribution of standardized languages for knowledge production, clinical reasoning and clinical Nursing practice. Rev. Bras. Enferm. 2013; 66(esp):134-41.

11. Bousso RS, Poles K, Cruz DALM. Conceitos e teorias na enfermagem. Rev. Esc. Enferm. USP 2014; 48(1):144-8.

12. Santos ER, Souza MF, Gutiérrez MGR, Maria VLR, Barros ALBL. Validation of the concept Risk for Decreased Cardiac Output. Rev. Latino-Am. Enferm. 2013;21(Spec):97-104.

13. Souza JM, Veríssimo MLÓR. Desenvolvimento infantil: análise de um novo conceito. Rev. LatinoAm. Enfermagem. 2015; 23(6):1097-104.

14. Romanzini AE, Carvalho EC, Galvão CM. Delayed surgical recovery: a concept analysis. Rev. Bras. Enferm. 2015; 68(5):668-75.

15. Santos SMJ, Araújo TL, Cavalcante TF, Galindo Neto, NM. Acute pain in myocardial infarction: analysis of concept. Rev. Gaúcha Enferm. 2015; 36(3): 102-8.

16. Guedes NG, Lopes MVO, Cavalcante TF, Moreira $\mathrm{RP}$, Araujo T. Review of nursing diagnosis sedentary lifestyle in individuals with hypertension: con- 
Renan Alves Silva • Álissan Karine Lima Martins • Natália Barreto de Castro Anna Virgínia Viana • Howard Karl Butcher • Viviane Martins da Silva

ceptual analysis. Rev. Esc. Enferm. USP. 2013; 47(3): 742-9.

17. Moysés AMB, Durant LC, Almeida AM, Gozzo TO. Revisão integrativa dos fatores relacionados do diagnóstico de enfermagem náusea na quimioterapia antineoplásica. Rev. Latino-Am. Enferm. 2016; 24:e2812.

18. Gonçalves RCS, Santana RF. Nursing diagnosis for material and sterilization center: concept analysis. Rev. Enferm. UFPE. 2016; 10(2):485-94.

19. Delphino TM, Santana RF, Souza PA. Concept clarification of «delayed surgical recovery» for clinical practice implementation. Rev. Enferm. Referência. 2015; 4(6):131-9.

20. Tornabeni J, Miller JF. The power of partnership to shape the future of nursing: the evolution of the Clinical Nurse Leader. J. Nursing Managem. 2008; 16:608-13.

21. Butcher H, Kirkpatrick HK. Powerlessness. In: McFarland G, Thomas MD (Eds.). Psychiatric mental health nursing: aplication of the nursing process. Philadelphia: Lippincott; 1991. P:370-7.

22. Miller JF. Coping with chronic illness: overcoming powerlessness (3rd ed.). Philadelphia: FA Davis; 2000.

23. Davidhizar R. Powerlessness of caregivers in home care. J. Clin. Nurs. 1994; 3(3):155-8.

24. Bright R. Grief and powerlessness: helping people regain control of their lives. Brsitol, PA: Jessica Kingsley Publishers; 1996.

25. Nyström AE, Segesten KM. On sources of powerlessness in nursing home life. J. Adv. Nurs. 1994;19:124-33.

26. Roberts SL, White BS. Powerlessness and personal control model applied to the myocardial infarction patient. Prog. Cardiovascul. Nurs. 1990; 5(3):84-94.

27. Braga CG, Cruz DALM. Powerlessness assessment tool for adult patients. Rev. Esc. Enferm. USP. 2009; 43(Spe):1062-9.

28. Zhang WN, Pan YH, Wang XY, Zhao Y. A prospective study of the incidence and correlated factors of post-stroke depression in china. PLoS One. 2013; 8(11):78-81.

29. Skidmore ER, Whyte EM, Holm MB, Becker JT, Butters MA, Dew MA, et al. Arch. Phys. Med. Rehabil. 2010; 91(2):203-7

30. Mitchell PH, Veith RC, Becker KJ, Buzaitis A, Cain $\mathrm{KC}$, Fruin $\mathrm{M}$, et al. Brief psychosocial-behavioral intervention with antidepressant reduces poststroke depression significantly more than usual care with antidepressant: living well with stroke: randomized, controlled trial. Stroke. 2009; 40(9): 3073-8.

31. Andrade NA, Fernandes MGM, Nóbrega MML, Garcia TR, Costa KNFM. Análise do conceito fragilidade em idosos. Rev Texto \& Context Enferm. 2012 21(4):748-56.

32. Ottenbacher KJ, Graham JE, Ottenbacher AJ, Lee J, Al Snih S, Karmarkar A et al. GV. Hospital readmission in persons with stroke following postacute inpatient rehabilitation. J. Gerontol. Biol. Sci. Med. Sci. 2012;67(8):875-81.

33. Barbosa AC, Medeiros LS, Duarte N, Meneses C. Factores preditivos de depressão pós-acidente vascular cerebral: estudo retrospectivo numa unidade de reabilitação. Acta Med. Port. 2011; 24(2):175-80.

34. Rabin BA, Burdea GC, Roll DT, Hundal JS, Damiani F, Pollack S. Integrative rehabilitation of elderly stroke survivors: the design and evaluation of the BrightArm. Disabil. Rehabil. Assist. Technol. 2012;7(4):323-35.

35. Thomas SA, Walker MF, Macniven JA, Haworth $\mathrm{H}$, Lincoln NB. Communication and Low Mood (CALM): a randomized controlled trial of behavioural therapy for stroke patients with aphasia. Clin. Rehabil. 2013;27(5):398-408.

36. Vickery CD. Assessment and correlates of selfesteem following stroke using a pictorial measure. Clin. Rehabil. 2006; 20(12):1075-84.

37. Tang WK, Chen YK, Lu JY, Chu WCW, Mok VCT, Ungvari GS, et al. Cerebral microbleeds and depression in lacunar stroke. Stroke. 2011; 42:2443-6.

38. Ayerbe L, Ayis S, Rudd AG, Heuschmann PU, Wolfe CD. Natural history, predictors, and associations of depression 5 years after stroke: the South London stroke register. Stroke. 2011; 42(7):1907-11.

39. Asplund K, Jonsson F, Eriksson M, Stegmayr B, Appelros P, Norrving B et al. Patient dissatisfaction with acute stroke care. Stroke. 2009; 40:3851-6.

40. Saxena SK, Ng TP, Yong D, Fong NP, Koh G. Functional outcomes in inpatient rehabilitative care of stroke patients: predictive factors and the effect of therapy intensity. Qual. Prim. Care. 2006:14(3): 145-53.

41. Kim DS, Park YG, Choi JH, Im SH, Jung KJ, Cha YA et al. Effects of music therapy on mood in stroke patients. Yonsei Med. J. 2011; 52(6): 977-81. 
42. Vickery CD, Sepehri A, Evans CC. Self-esteem in an acute stroke rehabilitation sample: a control group comparison. Clin. Rehabil. 2008; 22(2):179-87.

43. Kim MK, Kang SD. Effects of art therapy using color on purpose in life in patients with stroke and their caregivers. Yonsei Med. J. 2013; 54(1):15-20.

44. Chau JP, Thompson DR, Chang AM, Woo J. Psychometric properties of the Chinese version of State Self-Esteem Scale: an analysis of data from a cross-sectional survey of patients in the first four months after stroke. J. Clin. Nurs. 2012; 21(22):3268-75.

45. Roach SS. Introdução à enfermagem gerontológica. Rio de Janeiro: Guanabara Koogan; 2009.

46. Willey JZ, Disla N, Moon YP, Paik MC, Sacco RL, Boden-Albala B et al. Early depressed mood after stroke predicts long-term disability: the northern manhattan stroke study (NOMASS). Stroke. 2010; 41(9):1896-1900.

47. Hommel M, Trabucco-Miguel S, Naegele B, Gonnet $\mathrm{N}$, Jaillard $\mathrm{A}$. Cognitive determinants of so- cial functioning after a first ever mild to moderate stroke at vocational age. J. Neurol. Neurosurg. Psychiatr. 2009; 80(8):876-80.

48. Fonseca FB, Rizzotto MLF. Construção de instrumento para avaliação sócio-funcional em idosos. Texto Contexto -Enferm. 2008; 17(2):365-73.

49. Yang SY, Kong KH. Level and predictors of participation in patients with stroke undergoing inpatient rehabilitation. Singapore Med. J. 2013; 54(10):564-8.

50. Batcho CS, Stoquart G, Thonnard JL. Brisk walking can promote functional recovery in chronic stroke patients. J Rehabil. Med. 2013; 45(9):854-9.

51. Katayama M, Naritomi H, Oomura M, Nukata M, Yamamoto S, Araki $\mathrm{K}$ et al. Case reports of unexpected suicides in patients within six months after stroke. Kobe J. Med. Sci. 2011; 56(5):184-94.

52. Schulenberg SE, Schnetzer LW, Buchanan EM. The purpose in life test-short form: development and psychometric support. J. Happiness Stud. $2011 ; 12: 861-76$. 